\title{
Trajetória intelectual de pesquisadores da educação a fecundidade do estudo dos memoriais acadêmicos
}

TERESA CRISTINA REGO

Universidade de São Paulo, Butantã, SP, Brasil

RESUMO

$\mathrm{O}$ artigo apresenta os resultados de uma recente pesquisa realizada sobre o tema da constituição identitária, a educação, a memória e suas relações com as narrativas autobiográficas. Foram analisados doze memoriais apresentados em concursos para os mais altos cargos ou titulação da carreira universitária (livre-docência e titular), produzidos por professores ligados diretamente ou indiretamente aos estudos educacionais. Os memoriais examinados foram elaborados ao longo das últimas décadas por pesquisadores de duas diferentes gerações, selecionados com base nos seguintes critérios: expressão do pesquisador, diversidade em termos de formação, vinculação institucional e área de atuação. Buscou-se apreender elementos constitutivos próprios de uma identidade narrativa, bem como vozes sociais e polifônicas que perpassam esses relatos.

\section{PALAVRAS-CHAVE}

identidade narrativa; memorial; autobiografia. 


\title{
INTELLECTUAL TRAJECTORY OF RESEARCHERS \\ OF EDUCATION: THE FRUITFULNESS OF THE STUDY OF ACADEMIC MEMORIALS
}

\begin{abstract}
The article presents the results of a recent study on the theme of identity constitution, education, memory and their relations with autobiographical narratives. Twelve memorials were analyzed which were submitted in tenders for the highest positions or the highest titles of university careers; those memorials were written by teachers directly or indirectly connected to education studies. The examined memorials were written over the past decades by researchers from two different generations; they were selected based on the following criteria: significance of the researcher's work, diversity in terms of education, institutional affiliation and field. It was attempted to apprehend the constituent elements of a narrative identity, and social and polyphonic voices that permeate these reports.
\end{abstract}

KEYWORDS

narrative identities; memorials; autobiographical narratives.

\section{TRAYECTORIA INTELECTUAL DE INVESTIGADORES DE LA EDUCACIÓN: LA FECUNDIDAD DEL ESTUDIO DE LOS MEMORIALES ACADÉMICOS}

\section{RESUMEN}

El artículo presenta los resultados de un reciente estudio sobre el tema de la constitución de identidad, la educación, la memoria y sus relaciones con las narrativas autobiográficas. Fueron analizados doce memoriales presentados en concursos para los más altos cargos de titulación de la carrera universitaria, escritos por maestros conectados directa o indirectamente a los estudios de la educación. Los memoriales examinados fueron desarrollados en las últimas décadas por investigadores de dos generaciones diferentes, seleccionados con base en los siguientes criterios: la expresión del investigador, la diversidad en cuanto a la formación, vinculación institucional y área de actuación. Se buscó capturar elementos constitutivos propios de una identidad narrativa, y las voces sociales y polifónicas que impregnan estos informes.

\section{PALABRAS CLAVE}

identidad narrativa; memorial; autobiografía. 
Cada vez que nos colocamos diante do possivel, do que poderemos ser quando projetamos o futuro, toda vez que tomamos uma decisão que antecipa a ação que virá, o passado modifica-se, sofre uma releitura e adquire um novo significado. Desse modo, nós reescrevemos continuamente nossa jornada e a jornada do mundo. Nossa memória é seletiva e reconstrói a história do mundo e a nossa própria a partir do projeto. [...]

O nosso a manhã depende da matriz do passado, mas o que seremos relê e reelabora o que fomos. O presente é o único horizonte possivel para essa ligação: a presença é o lugar em que passado e futuro podem estar numa relação circular. É no presente que o passado reflete sua luz e sua sombra sobre o futuro e que este ilumina ou turva aquela porção de nós mesmos na qual queremos ou podemos nos reconhecer.

Melucci, 2004, p. 23

As reflexões aqui apresentadas estão relacionadas às investigações desenvolvidas no campo da psicologia do desenvolvimento e da educação. Com base na psicologia histórico-cultural (Valsiner; Rosa, 2007; Vigotski, 2000) e em outras fontes teóricas, tenho realizado estudos acerca da constituição da subjetividade por meio dos modos pelos quais o sujeito narra sua própria vida (Oliveira; Rego; Aquino, 2006; Rego, 2003). O texto que se segue consiste num exercício reflexivo com base nos resultados de uma recente pesquisa realizada sobre o tema da constituição identitária, a educação, a memória e suas relações com as narrativas autobiográficas.

Além da investigação de caráter estritamente teórico, a pesquisa empírica foi realizada por meio da análise de um gênero de escrita de grande tradição na universidade pública brasileira: os memoriais acadêmicos. Os textos - espécie de autobiografia intelectual e profissional de professores universitários - costumam ser exigidos nos processos seletivos ou de ascensão na carreira acadêmica. Embora constitua fonte fecunda para a pesquisa de diferentes âmbitos, os memoriais não têm sido suficientemente explorados. ${ }^{1}$

No caso da pesquisa concluída, foram analisados vinte memoriais apresentados em concursos para os mais altos cargos ou titulação da carreira universitária, produzidos por professores ligados diretamente ao campo da educação ou que, embora egressos de outras áreas, trazem insumos importantes aos estudos educacionais. ${ }^{2} \mathrm{Na}$ investigação realizada a proposta foi a de coletar e examinar memoriais

1 Nesse sentido, os trabalhos pioneiros de Passeggi (2008) e do grupo de pesquisadores por ela coordenado sobre esse gênero autobiográfico constituem-se em importante exceção.

2 O projeto de pesquisa intitulado "A educação e a construção de processos identitários: o memorial como fonte de estudo" contou com o apoio do Conselho Nacional de Desenvolvimento Científico e Tecnológico (CNPq) - bolsa produtividade em pesquisa; triênio 2009-2011/processo 30824212008-4. Durante o ano de 2009, quatro estudantes 
(apresentados por ocasião de concurso para livre-docência ou para professor titular), produzidos ao longo das últimas décadas, por pesquisadores de ambos os sexos (dez homens e dez mulheres) e de duas diferentes gerações, selecionados com base nos seguintes critérios: expressão do pesquisador, diversidade em termos de formação, vinculação institucional e área de atuação.

Sendo assim, a metodologia foi desenvolvida com base em dois procedimentos principais: a pesquisa bibliográfica e o exame das narrativas autobiográficas. Buscou-se apreender, nessas narrativas, elementos constitutivos próprios de uma memória coletiva e discursiva, bem como vozes sociais e polifônicas que perpassam esses relatos. Do ponto de vista da pesquisa, a intenção, todavia, não foi a de empregar dados biográficos para ilustrar formas típicas de comportamento, mas a de investigar a interdependência de fatores que originaram combinações específicas na história de vida de cada sujeito, especialmente no que diz respeito a sua trajetória acadêmica e a seu percurso intelectual. Foi dada especial atenção aos contextos de desenvolvimento e ao modo ativo de o sujeito internalizar os fatores culturais e de interagir com outros sujeitos e mediadores.

Após um primeiro levantamento de dados na Plataforma Lattes, cujo objetivo foi mapear alguns dados pessoais e profissionais sobre os indivíduos pesquisados, num segundo momento o principal foco do projeto se constituiu na análise dos memoriais acadêmicos dos professores selecionados. Nas leituras e análises dos materiais, procurava-se levar em consideração os seguintes temas e aspectos específicos:

1. Dados gerais (nome, instituição, áreas de atuação, razão da apresentação do memorial, ano de elaboração e número de páginas);

2. Características do memorial (organização e estrutura da narrativa adotada e comentários sobre a tarefa de escrever um memorial);

3. Análise do conteúdo do memorial (Seleção e exame de trechos relacionados aos seguintes temas: vida familiar; vida escolar; formação universitária; relações com o contexto político do país ou com a política educacional; reflexões sobre a prática no ensino superior; visão sobre as condições da universidade contemporânea; relações com o saber, pessoas marcantes e autores específicos; e a gênese de seu envolvimento com educação e do interesse por seus temas de pesquisa; presença do acaso, do imponderável, acidental ou imprevisível; modo como se apresenta, se define e justifica sua trajetória profissional e acadêmica).

A pesquisa realizada permitiu a elaboração de um balanço sobre aspectos da vida e obra de alguns dos mais expressivos autores atuais, considerados importantes

de iniciação científica estiveram envolvidas no desenvolvimento dessa investigação, duas com bolsa de pesquisa: Neffertite Marques da Costa (Programa Institucional de Bolsas de Iniciação Científica - PIBIC/CNPq), Samanta Benfica Jarussi (Bolsa Santander), Anna Neaime Cunha (sem bolsa) e Paula Carolina Dias Tonetto (sem bolsa). 
especialistas nacionais das mais representativas universidades do país, reconhecidos como pesquisadores contemporâneos de destaque, cuja obra vem trazendo alguma contribuição ao estudo e à compreensão da problemática educacional. Possibilitou também dar respostas a uma série de perguntas, tais como: Como se formaram os que hoje formam os professores? O que é preciso para tornar-se um educador e um pesquisador na área da educação? Que espécie de sacrifícios e recompensas marcaram uma vida dedicada à universidade e à educação? Como foram gestados os temas de pesquisa deles? Quais foram suas principais influências? Quem foram seus professores mais marcantes? Quais foram as principais dificuldades enfrentadas ao longo da carreira?

Os memoriais se revelaram uma amostra modesta, porém vigorosa, do que vem sendo produzido no campo da educação por pensadores de grande prestígio no meio acadêmico e educacional brasileiro. Mais do que isso, uma real oportunidade de o autor desenvolver ideias, explicar trabalhos e conquistas, deixando-se que o próprio sujeito apresente quem ele é e que avalie, de modo crítico, sua relação com a educação. Enfim, os memoriais permitiram conhecer o ponto de vista crítico e metateórico do pesquisador ao analisar seu próprio percurso de formação e produção acadêmica ao longo dos anos dedicados à atuação ou pesquisa na área da educação, explicitando aspectos que a leitura direta de textos dispersos dos pensadores nem sempre revela.

Sendo assim, a análise dos memoriais ensejou um conjunto repleto de pistas importantes, capazes de desenhar uma espécie de cartografia da trajetória intelectual de pesquisadores de destaque na educação e do modo como suas ideias foram sendo construídas e engendradas. Possibilitou também um retrato da diversidade de temas que preocupam o universo acadêmico, os quais estão, por sua vez, relacionados aos problemas concretos presentes na realidade educacional brasileira. Finalmente, os memoriais mostraram-se potencialmente interessantes pelo fato de permitirem identificar a variedade de objetos e métodos adotados, os pontos de convergência e distanciamento entre os autores estudados e, sobretudo, as permanências, rupturas e desafios da produção contemporânea e suas interfaces com a educação.

A despeito das singularidades que caracterizam cada um dos memoriais que foram escolhidos, houve entre eles alguns temas recorrentes, que permitiram que fossem articulados não só do ponto de vista dos objetivos mais gerais, como também em termos dos referenciais nos quais estão firmados, especialmente no que diz respeito ao formato e estilo da narrativa adotada, tema que será explorado neste artigo.

A pretensão é a de que os resultados dessas análises tragam novos elementos não somente para o estudo do gênero memorialístico, mas principalmente para que sejam capazes de provocar novas interrogações e perspectivas de exame para os estudos da educação no passado e no presente, bem como do ofício do pesquisador em educação. 


\section{AS COMPLEXAS RELAÇÕES ENTRE MEMÓRIA, NARRATIVA E IDENTIDADE}

O interesse pelo relato na primeira pessoa e pela razão do sujeito, que expõe sua vida (pública, privada, afetiva ou política) de diferentes formas e em diversos meios, nunca despertou tanta atração como atualmente (Sarlo, 2007). Como reflexo desse entusiasmo, há uma inegável febre do uso da primeira pessoa em diferentes modalidades de textos (jornalísticos, literários, ensaios acadêmicos etc.). Pária no mundo científico, tradicional excluído dos meios da não ficção, malvisto no campo do jornalismo, o "eu" aparece hoje de modo triunfal e impositivo.

É curioso observar que, a bem da verdade, esse interesse já ultrapassou há um bom tempo o meio ficcional e ocupa lugar privilegiado no chamado jornalismo cultural, e até nos meios acadêmicos, em diferentes áreas das ciências humanas e sociais. Histórias de vida e autobiografias sobre figuras de destaque, personagens excepcionais ou mesmo pessoas comuns retratadas por meio de documentários, diários, entrevistas e outras modalidades similares, encontram destaque no mercado editorial, na indústria cinematográfica das últimas décadas (do circuito comercial ao alternativo) e crescente prestígio nas universidades de vanguarda.

Adotar a primeira pessoa do singular virou, indubitavelmente, uma moda e até uma praga na escrita e na produção artística e acadêmica contemporânea. Se o resultado, em alguns casos, é discutível, o princípio é mais que razoável e compreensível. Não há mesmo porque banir a subjetividade da escrita, já que a terceira pessoa e sua pretensão à neutralidade e à seriedade não são, em si, garantia de absolutamente nada. Ou seja, do ponto de vista científico, o fato de o sujeito adotar um tom mais intimista não representa maior ou menor distinção intelectual, tampouco é indicador do grau de dificuldade e aridez do pedregoso trajeto acadêmico trilhado.

Todavia, o que nem sempre parece ficar suficientemente claro é que nenhuma (auto)biografia (em forma de livro, filme ou documentário), por mais bem elaborada que seja, conseguirá reconstituir o personagem na sua complexidade e integridade, tampouco o tempo vivido na sua inteireza. Ela será sempre um olhar, um recorte entre muitos outros possíveis, que busca apreender e registrar, a posteriori, a complexidade de um ser humano, que sempre é múltiplo, dinâmico, composto pelas experiências vividas e imaginadas, pelas fantasias e projetos sonhados e realizados. Assim como nenhuma pessoa cabe inteiramente em uma biografia, nenhuma biografia é definitiva. Ou seja, nenhuma narrativa de cunho autobiográfico será capaz de esgotar a labiríntica figura daquele que a escreve ou que a narra.

$\mathrm{Na}$ esteira do que aponta Melucci na epígrafe deste texto, sabemos que as memórias do tempo passado são sempre fugidias e sujeitas a novas interpretações e reconfigurações. Cada vez que organizamos uma narrativa sobre aquilo que vivemos, alteramos a frágil composição do terreno em que as memórias se assentam. O passado nunca está totalmente encerrado e concluído. Ele age e se reconfigura 
sem que o saibamos, ambíguo, desafiador e potente. Há fases em que ele parece adormecido, como se só importasse o cotidiano atribulado e os projetos para o futuro, sempre incerto. Mas em outros momentos ele ressurge, com uma força que se projeta sobre o presente, trazendo velhos fatos e episódios, com novos temas e intrigantes questões que precisam ser novamente decifrados ou interpretados. Aspectos que em outras épocas pareciam não ter muita importância adquirem num outro momento outra dimensão. Nesse movimento, algumas experiências vividas precisavam ser recuperadas, decifradas e ressignificadas para dar algum tipo de sentido e identidade à nossa história (Arida, 2011).

Nessas novas versões sobre o vivido, revemos ou incluímos algumas novas passagens, alteramos algumas ênfases e, principalmente, atualizamos as informações que envolvem os anos mais recentes. Como adverte Candido (2012, p. 15), lembrar é também uma tentativa de "manter na mão o fio que nos liga a nós mesmos" nas permanentes transformações que vivemos a cada instante:

a memória é um laboratório oculto onde se dão à nossa revelia combinações inesperadas e arbitrárias. É ilusório pensar que seja um depósito ou arquivo, nos quais ficam guardadas as recordações, que podemos retirar e consultar como se reproduzissem exatamente os acontecimentos idos e vividos. Nada disso. No entanto, ela é o recurso de que dispomos para sentirmos a própria identidade e sabermos se ainda somos mesmo nós, na caudal do tempo que nos modifica sem cessar. (idem, ibidem)

Enfim, reordenamos o discurso e o mosaico de fragmentos de emoções, lembranças e fatos que aparecem justapostos ou esmaecidos no ar do presente. Esse é sempre um jogo arriscado e provisório. Uma tentativa de deter o tempo, ou de captar o retrato - como o abrir e o fechar de uma objetiva - de alguma coisa vívida, sem contornos muito definidos e em permanente construção.

\section{A FECUNDIDADE DOS ESTUDOS DOS MEMORIAIS ACADÊMICOS}

Embora reconheça esses limites, acredito que o memorial, somado a outros elementos, pode auxiliar tanto o processo de avaliação de um percurso intelectual como a qualidade da produção científica dele resultante. Como bem observou Soares (2001, p. 25, grifos do original), escrevê-lo é, portanto, um momento privilegiado para o sujeito fazer um balanço sobre um passado acadêmico construído:

fazer uma tese cujo objeto é a própria vida acadêmica (pois isto é o memorial) obriga o professor universitário a ultrapassar o que fez, em sua vida acadêmica, para determinar por que fez, para que fez e como fez; ou seja: além da enumeração, que está em seu Curriculum Vitae, a análise, a crítica, a justificativa”. E mais: o memorial só é possível a quem tem um passado acadêmico para contar, e só a esses deveria ser oferecido o acesso ao último degrau da carreira docente universitária. 
Elaborar um memorial não é, todavia, uma tarefa fácil. Larrosa (2002, p. 21) faz uma análise arguta da complexidade envolvida na tarefa, quando afirma que nomear o que somos ou "o que fazemos, em educação ou em qualquer outro lugar, como técnica aplicada, como práxis reflexiva ou como experiência dotada de sentido, não é somente uma questão terminológica”. O uso das palavras é, sem dúvida, um tema bem mais complexo do que aparenta ser.

Entre outros aspectos, é importante ressaltar que o memorial, além de ser polissêmico é também polifônico, já que outras falas perpassam os relatos (Bakhtin, 1992; Wertsch, 2002). Dito de outra maneira: ele não contém uma verdade em si, pois esta depende da situação, das motivações e das referências culturais de quem o escreve e de quem o lê. A vida não está lá, portanto, no texto, mas nas orientações de quem o elabora e de quem o interpreta. De certo modo, quem escreve o memorial faz o que quer, consegue e pode fazer (no sentido de ter a permissão, o poder de realizar).

Do mesmo modo, cada narrativa sugere ao leitor formas singulares de apreensão daquilo que é narrado (Ricoeur, 1995). Quem lê o conteúdo elaborado num memorial, por sua vez, o apreende sob as pressões do lugar que ocupa, o qual, igualmente, nunca é neutro. Dificilmente um leitor na posição de avaliador, por exemplo como membro de uma banca de julgamento, no caso de um concurso, terá condições de reconhecer alguém em um memorial com a objetividade que se supõe existir no processo envolvido. Não importa. Essas são as regras do jogo. $\mathrm{O}$ importante é estar atento a elas.

Mas o reconhecimento das limitações do memorial (daquilo que poderíamos chamar de seu "calcanhar de aquiles") talvez seja a forma pela qual se possa vislumbrar melhor suas potencialidades. Ou seja, naquilo que poderíamos julgar como sendo sua vulnerabilidade ou debilidade, esconde-se justamente uma de suas maiores qualidades: cada memorial vai muito além da tentativa ingênua de retratar ou reconstituir, com exatidão, "a vida tal como ela foi vivida". Ao contrário disso, por mais conservador que ele possa aparentar ser (do ponto de vista de seu formato ou do conteúdo apresentado), ele sugere de modo recorrente uma espécie de estética do inacabado e insinua a importante lembrança de que, no que se refere à vida, há sempre o sentido da impermanência, do movimento - muitas vezes imperceptível das coisas, pessoas, valores e lugares.

O memorial indica ainda que, no que se refere ao conhecimento, ninguém constrói nada sozinho: ele sempre é fruto de um longo processo de intercâmbios, diálogos e trocas de repertórios e práticas culturais. De certo modo, ele permite confirmar a tese levantada por Vygotski (2000) de que, no que se refere à natureza das funções mentais mais complexas (tipicamente humanas), o percurso obedece ao seguinte sentido: do interpsíquico para o intrapsíquico, já que elas resultam de relações sociais ativamente internalizadas.

Finalmente, ele confirma também que as memórias e as narrativas, assim como as vidas, são sempre singulares. Por esse conjunto de razões, por meio dessas narrativas, ainda que de um modo errático e único, é possível enxergar através de 
novos ângulos partes importantes da condição humana, que pertencem ao lado de dentro e ao de fora, ao avesso e ao direito, ao universal e ao local, ao geral e ao específico, ao singular e ao plural, às partes visíveis e àquelas que não se veem, ao dito e ao interdito.

\section{ALGUNS RESULTADOS DA PESQUISA REALIZADA}

É interessante comentar que quando iniciei a pesquisa com memoriais, embora estivesse com grande motivação teórico-metodológica, afligia-me constatar que, apesar da cobrança constante da apresentação desse tipo de documento e de sua arguição como componente importante de concursos e provas no meio acadêmico das universidades públicas brasileiras, como elemento capaz de comprovar (somado a uma série de outras exigências), a uma comissão julgadora, competências e pré-requisitos formais do candidato para fins de obtenção de título, ascensão de carreira, ingresso na carreira docente ou concursos de efetivação, havia significativa escassez de estudos e debates em torno do tema. Surprendia-me também com a ausência de orientações institucionais mais claras sobre como fazer os memoriais.

Ao mesmo tempo, à medida que lia memoriais de modo mais sistemático, achava curioso constatar uma espécie de conformismo, de obediência e de atitude pouco questionadora por expressiva parte dos professores-memorialistas. Estranhava o fato de alguns autores dos textos parecerem não apresentar, ao menos de modo declarado, recusa, incômodo ou algum tipo de resistência à tarefa. Era intrigante observar também que os memoriais sempre apresentavam formatos diferentes, expressando marcas de autoria, mas que a maior parte dos autores analisados não arriscava modos mais inventivos, criativos de "contar sua trajetória".

Embora reconhecesse nesses traços o reflexo das circunstâncias, do caráter compulsório da avaliação e da imposição de certos parâmetros e limites relacionados ao formato do memorial exigido (sobretudo ao fato de o sujeito-autor escrever para um leitor que não faz uma leitura desinteressada, ao contrário, é um leitor que, autorizado pelos cânones acadêmicos, avalia a qualidade e legitimidade da trajetória acadêmica exposta e que, por fim, julga os méritos à vaga ou ao cargo ao qual o candidato aspira), comecei a constatar, ainda mais surpresa, que parte significativa dos professores - entre eles até os mais reconhecidos por seu espírito combativo, por seu alto grau de exigência crítica, ou pela sua costumeira análise fina dos objetos de seu campo de conhecimento -, quando instados a falar de si e relatar sua trajetória, assumiam um discurso pouco crítico, às vezes frágil e até ingênuo.

Reparei, por exemplo, que alguns iniciavam o texto sem tecer nenhuma consideração sobre os riscos envolvidos na escrita desse tipo de documento. Outros, já nos paragráfos introdutórios, além de certa idealização do passado, deixavam transparecer que talvez acreditassem na noção de trajetória como desígnio, forçando aquilo que Bourdieu (2005) tão bem criticou no seu ácido texto "A ilusão biográfica": a criação artificial de sentido para eventos aleatórios ou relacionados às circunstâncias histórico-culturais, consubstanciada na adoção de um modo de 
interpretar e apresentar a história de vida e os processos individuais como um conjunto coerente, coeso, ordenado e orientado, originário de um projeto - subjetivo e objetivo - original, essa criação era traduzida nas expressões: "desde muito cedo", "desde o início", "desde sempre”, "desde que me entendo por gente", "quando ainda era criança", "já ao nascer" ou "sempre gostei de música" etc. (idem, p. 183-191).

Observei também que muitos apresentavam uma espécie de tom triunfalista, épico, autoelogioso, parecendo querer (ou precisar?) pintar um retrato edulcorado e irretocável de um personagem com vocação (quase sempre já manifesta na infância ou nos primeiros tempos de escola) para a docência e as lides do mundo acadêmico. Muitos tendiam a forçar a apresentação de uma pretensa personagem inteiriça, compacta, totalizadora, definitiva, quase olímpica, sem vestígio de hesitação, tormento ou dúvida. Outros, usando os artifícios e recursos da estilística, pareciam tentar justificar o injustificável, ordenar o inordenável, corrigir rotas já percorridas, refazer argumentos para opções já feitas e encontrar lógica e encadeamentos onde nem sempre estes existiram. Deixavam transparecer que procuravam estabelecer, $a$ posteriori, algum tipo de solidez para as experiências e controle, senão da vida, pelo menos das recordações do passado.

Surpreendia-me com o que lia, pois considerava que confrontar, polemizar e criticar são atitudes previstas e louváveis na linha de frente da produção acadêmica (especialmente no campo das ciências humanas e sociais). Todavia, em muitos memoriais estudados o tom dominante resvalava no clichê: vitória, superação e, sobretudo, a moral do "bom comportamento". Muitos autores buscavam falar de um lugar, geralmente confortável e privilegiado, a que julgavam, todos, pertencer (por menos confortável que, em alguns casos, parecesse ser ocupá-lo).

Há, por exemplo, os que se apresentam como ex-estudante exemplar (na escola básica ou na universidade) ou como cidadão politicamente correto, virtuoso, atento às injustiças e à crueldade do mundo em que vive, capaz de reunir, a um só tempo, todas as virtudes sociais valorizadas no mundo contemporâneo (por exemplo: vários se apresentam como ex-militantes combativos durante os anos da ditadura militar no Brasil). Muitos deixam transparecer que foram bem cuidados desde o berço, nascidos no seio de famílias de classe média ou média alta. Contam que foram educados para cultuar a escola, o saber, os livros, para preservar o planeta e se solidarizar com o próximo. Muitos declaram terem respeitado, desde cedo, as diferenças de gênero, etnia, crenças, aptidões e classes sociais, e se colocam formalmente contra toda e qualquer forma de autoritarismo. Não raramente se apresentam como ativistas de movimentos sociais e causas humanitárias e como funcionários exemplares de uma instituição pública voltada à construção de conhecimento e dedicada ao bem-estar geral da sociedade.

Finalmente reparei que um número menor de autores, aparentemente constrangidos por expor seu percurso de formação, traços de sua história familiar, ou mesmo por tecer algum comentário sobre si mesmos, aludem muito brevemente a esse período, a esse universo temático ou a tudo que se relacionasse ao mundo privado, detendo-se numa descrição mais detalhada do exercício da docência, da 
pesquisa e da extensão, bem como do conjunto de atividades administrativas com as quais se depararam ao longo de sua carreira universitária.

Mas houve, entre os memoriais analisados, autores que, embora conscientes das restrições do gênero, conseguiram elaborar textos criativos, críticos e metateóricos. ${ }^{3}$

Obviamente, vários são os fatores que poderiam justificar tal estado de coisas, que vão do estilo adotado pelos autores, passando pelas motivações pessoais e até pelas circunstâncias políticas e institucionais em que o documento foi elaborado ou a que se destinou. Impossível, portanto, esquadrinhar caso a caso as inúmeras variáveis que podem estar relacionadas ao fato de o candidato/autor ter elaborado um documento mais ou menos reflexivo ou crítico sobre a tarefa de escrever um memorial. Embora reconheça os limites desse esforço, proponho três hipóteses que, no meu entender, ajudam a compreender, ainda que parcialmente, as razões para que esse tipo de documento tenha adquirido tais perfis.

\section{GÊNERO DE ESCRITA: COMO DEVO ME APRESENTAR?}

A primeira hipótese está relacionada às restrições decorrentes daquilo que poderíamos chamar de gênero de escrita, que impõe certas normas, padrões e limites para a narrativa, conforme comentarei a seguir. Antes, porém, é importante esclarecer que não tenho a pretensão de chegar a uma definição universal do gênero memorial, nem a definições gerais que tentem descrever uma suposta essência capaz de englobar todos os sentidos e as características desse tipo de escrita. Isso seria um contrassenso já que, como alerta Cândido (1992), a própria ideia de delimitação dos diversos gêneros literários se mostra frágil e duvidosa. Minha contribuição será bem mais modesta: apenas buscarei circunscrever alguns traços que caracterizam e restringem essa narrativa.

É interessante observar que o memorial é um tipo de escrita acadêmica de grande tradição no ensino superior, intimamente relacionada à criação da universidade pública brasileira, que teve início na década de 1930. Embora não seja uma prática antiga, até hoje não existe uma orientação muito clara do que deve estar contido num memorial (há apenas algumas exigências breves nos textos dos editais

3 Temos dois exemplos de memoriais com esse perfil que felizmente viraram livro, permitindo o acesso de um número amplo de leitores: o já clássico livro Metamemória memórias: travessias de uma educadora, de Magda Becker Soares (2001), e o recém-lançado Cultura Es psicologia: questóes sobre o desenvolvimento do adulto (2009), de autoria de Marta Kohl de Oliveira. Nos memoriais publicados (elaborados para fins de concurso e progressão na carreira acadêmica), duas das mais respeitadas pesquisadoras do país no campo da educação constroem uma espécie de autobiografia intelectual, permitindo que o leitor compartilhe o ponto de vista crítico e metateórico delas acerca de seu próprio percurso de formação e produção acadêmica ao longo de décadas dedicadas à universidade, bem como aspectos relevantes envolvidos nos processos de construção de conhecimento e de constituição de singularidades, temas de grande relevância no debate das ciências humanas e sociais contemporâneas. 
dos concursos), há, em nosso meio acadêmico, uma espécie de acordo tácito sobre o que se espera desse tipo de documento: um texto de cunho autobiográfico, capaz de fornecer ao leitor, sob a forma de um relato histórico e analítico, esclarecimentos (sobre fatos e acontecimentos) que permitam compreender o itinerário intelectual e profissional percorrido, assim como os planos e objetivos para a carreira num futuro próximo. Ou seja, espera-se que o candidato (ao cargo ou título) seja capaz de descrever e analisar certos aspectos presentes na sua trajetória de formação, tais como motivações para sua escolha profissional, características de suas atividades de ensino, pesquisa e extensão - com destaque para seu trabalho como orientador de novos investigadores e como construtor de uma linha de pesquisa -, os quais justifiquem seu mérito à vaga ou ao posto pleiteado (Passeggi, 2008).

Para compreender melhor a peculiaridade do memorial acadêmico e alguns de seus vieses, é relevante também analisar suas definições, seus significados e sentidos do ponto de vista linguístico e etimológico. Segundo o Dicionário Houaiss da lingua portuguesa, o termo "memorial" (século XIV), do latim tardio memoriale ("aquilo que faz lembrar"), pode ser definido, entre outras características, como: “[...] Digno de ser lembrado; memorável” (Houaiss, 2001, p. 1.890).

Embora haja alguma variação de acordo com a área do conhecimento em que se aplica, pode-se notar que, longe de ser uma narrativa autobiográfica espontânea, descompromissada, despretensiosa e desinteressada, em que caberia a descrição ou a rememoração de quaisquer fatos e acontecimentos marcantes, o memorial impõe uma série de restrições - para não dizer constrangimentos - para quem o escreve: primeiramente ele deve relatar especialmente "aquilo que merece ser lembrado" e que ficará para a posteridade. ${ }^{4}$ No caso específico do universo acadêmico: há um pressuposto implícito de que o que deve ser enaltecido são os méritos, as aspirações, os fatos ou feitos, as realizações científicas memoráveis de um indivíduo ou de uma coletividade científica. Por outro lado, isso pressupõe também, obviamente, fazer calar aquilo que deve ser esquecido.

Na prática, sabemos que a vida nas instituições acadêmicas - como, aliás, em qualquer instituição - não é um mar de rosas. Ao lado de grandes feitos científicos e sociais, há também, com frequência, uma série de problemas que marcam o cotidiano das universidades. Todavia, referências explícitas a esses elementos quase

4 Nesse caso há certa ambiguidade que se traduz no modo como esses documentos - em tese públicos e elaborados com o intuito de não serem textos efêmeros e passageiros, mas feitos para a posteridade - são, depois de julgados nos concursos, conservados e disponibilizados para os leitores e investigadores em potencial. Na maior parte das vezes o pesquisador interessado em acessar essa documentação encontra enorme dificuldade, pois nem sempre os memoriais estão disponíveis nas bibliotecas das respectivas faculdades em que eles foram apresentados, já que esta não é uma prática obrigatória nem, tampouco, rotineira. Alguns professores e secretarias encaminham alguns exemplares às bibliotecas, mas, infelizmente, este não é um procedimento adotado em todas as universidades e faculdades públicas. Na maior parte das vezes, o destino desses textos são as gavetas e estantes inacessíveis de alguma sala onde se guardam os inúmeros processos burocráticos que tramitam pelas instituições. 
não apareceram nos memoriais estudados. O historiador inglês Peter Burke (2003, p. 12), que estudou traços que caracterizam o gênero literário de cunho autobiográgico, ajuda-nos a entender por que esses problemas institucionais aparecem de modo tão discreto:

Autobiografias e livros de memórias constituem maneiras especialmente eficazes para as pessoas apresentarem o que pode se chamar de "a versão autorizada" de suas vidas, fazendo crer que buscaram determinadas metas sem as hesitações, os desvios e as confusões que fazem parte da vida de todas as pessoas. $\mathrm{Pu}-$ blicar cartas é o outro meio usado para o mesmo fim [...]. Se queremos detalhes sobre a vida de uma pessoa, coletâneas de cartas como essa devem ser vistas com alguma desconfiança, e a mesma coisa se aplica a autobiografias e livros de memórias. Mesmo assim, são inestimáveis como documentos que revelam a autoimagem da pessoa. Como diz Foster sobre o relato feito por Yeats de sua infância e juventude, ele diz mais sobre o poeta como ele era em 1914, ano em que o escreveu, do que como era em sua infância.

Não devemos ignorar, entretanto, o fato de que o memorial se constitui, antes de mais nada, num instrumento de avaliação de competência e mérito de um percurso acadêmico-profissional, a ser examinado por uma comissão julgadora. Dessa avaliação, entre outros itens, dependerá o sucesso ou o fracasso da empreitada em que o candidato se encontra envolvido. Essa talvez seja uma das principais caraterísticas que definem as marcas desse tipo de documento. Não se trata, assim, de um gênero simples. Em contraste com o protocolo narrativo autobiográfico, o memorial estabelece entre o autor e o leitor uma série de mediações e filtros singulares. A leitura dos memoriais demanda, portanto, que seus intérpretes aliem a atenção às redes de interlocução, com base nas quais eles são escritos, ao esforço cuidadoso para decifrar e procurar entender o processo de sua elaboração narrativa, bem como o enfrentamento das armadilhas e obstáculos pertinentes a esse tipo de escrita.

Em síntese, minha primeira hipótese é de que o gênero e o contexto em que o memorial é produzido (como peça de avaliação) dão à narrativa um "tom de balanço", como uma tentativa do sujeito de justificar o passado para acertar contas com seu presente. É curioso observar que "esse acerto de contas" assume variados e interessantes formatos: alguns autores, por exemplo, assumem uma espécie de tom confessional, revelando fatos ou episódios ainda desconhecidos; outros expõem ressentimentos com alguns colegas, grupos, com a instituição ou com a sociedade de maneira geral. Há também aqueles que fazem homenagens a amigos e parceiros de trabalhos ou comentam coisas que não tiveram coragem ou oportunidade de falar pessoalmente. Enfim, revelam um amplo conjunto de sentimentos que podem ir da gratidão e acolhimento até a revolta, mágoa, desilusão ou desconfiança.

Ou seja, longe de simplesmente trazer à tona determinadas lembranças, há uma busca (deliberada ou não) de persuadir o leitor (que, pelas circunstâncias, mais se aproxima da figura de um avaliador), de convencê-lo de seu valor, honra, mérito e dedicação ao universo intelectual. As formas por meio das quais os autores 
tentam realizar tal intento são variadas. Algumas são sutis e discretas, outras mais explícitas, mas todos autores se mostram igualmente empenhados na tarefa de construir um perfil apresentável e afinado com aquilo que é valorizado e aceito nos meios acadêmicos.

Obviamente, isso é dinâmico e, portanto, passível de mudanças de acordo com os diferentes tempos históricos e com as pressões que caracterizam cada época. Hoje, por exemplo, o "notório saber" de um professor é avaliado, principalmente, pela qualidade e quantidade de sua produção bibliográfica, aspecto comentado a seguir.

\section{TEXTO E CONTEXTO: QUAIS SÃO OS VALORES, PESOS E MEDIDAS EM JOGO?}

A segunda hipótese decorre da primeira e diz respeito à necessidade de considerar a íntima relação entre texto e contexto. Em outras palavras, o tom assumido na narrativa prende-se à realidade e espelha os impasses éticos, os dilemas morais, as aflições pessoais e as posturas e/ou pressões políticas que interferem na concepção do documento, truncando textos ou forçando sua reelaboração em meio ao processo de escrita. É importante, então, que nos perguntemos: em que contexto (e em que tempo histórico) esses textos foram produzidos? Quais foram as preocupações da época? Quais as pressões existentes no ensino universitário do período?

De certo modo, os memoriais possibilitam conhecer, entre muitos outros aspectos (como relatos de experiências escolares, memórias de instituições e de práticas de ensino, procedimentos de pesquisa, temas de investigação em voga em cada época, métodos de formação docente etc.), alguns dos valores que circulam na comunidade acadêmica em diferentes contextos, culturas e períodos históricos.

O estudo de memoriais produzidos nas últimas três décadas, por exemplo, permite constatar a ocorrência de uma série de transformações sociais, políticas, culturais, tecnológicas e econômicas substantivas que envolveram toda a sociedade. Da mesma forma, os memoriais testemunham as mudanças ocorridas na realidade educacional brasileira, as quais afetaram as universidades e o cenário das publicações científicas (e que, de algum modo, tiveram de ser enfrentadas pelos professores universitários). Nesse aspecto há o que ser celebrado, mas também há muito para se problematizar. Os memoriais escritos mais recentemente retratam, com fidelidade, a angústia decorrente do ritmo de trabalho frenético que vem definindo as últimas décadas e que marcam, irredutivelmente, o tempo em que vivemos.

Um dos traços que mais chama atenção, ao analisar o conjunto de memoriais selecionados em duas diferentes gerações de professores, é o modo como, num intervalo relativamente pequeno de tempo, passamos - ao menos no que diz respeito à produção nas ciências humanas - a produzir em contexto, ritmo e tempo muito diferentes daqueles vividos por quem começou a atuar no magistério superior em outras décadas. Indubitavelmente o tempo presente é marcado pelo sentimento de urgência, de pressa, pela cobrança desenfreada, pela competição desmedida, pela 
eterna vigilância e avaliação, pelos perversos mecanismos de prestação de contas e mensuração de "eficiência". ${ }^{5}$

A esse respeito, a socióloga francesa Claudine Haroche (2011, p. 659) apresenta, no ensaio "O inavaliável em uma sociedade de desconfiança", os dilemas trazidos pelas avaliações de desempenho e pelos controversos métodos de premiação e estímulo à "produtividade", tão presentes nos meios acadêmicos contemporâneos e refletidos nos textos dos memoriais atuais:

Vivemos presentemente em sociedades de controle contínuo que induzem e reforçam a falta de confiança e, além disso, uma desconfiança difusa e crescente que nos leva a falar de sociedade de desconfiança. Nestas sociedades exige-se tanto dos organismos como dos indivíduos que prestem conta, com precisão, não tanto daquilo que fizeram, mas do que fazem no momento presente, assim como o que pretendem fazer: procura-se assim suprimir a perda de tempo, a falta de rentabilidade e, mais ainda, o imprevisível, inavaliável por definição. Em face do ininteligível provocado e intensificado pela mudança permanente, ligada entre outras coisas à aceleração das tecnologias, a sociedade foi levada a desenvolver ferramentas de avaliação; indiferente ao indivíduo em sua singularidade, a avaliação tende a individualizá-lo e controlá-lo incessantemente e, ao mesmo tempo, a diferenciá-lo e homogeneizá-lo cada vez mais. Atualmente, os bens e as pessoas são cada vez mais avaliados e, portanto, inevitavelmente comparados, engendrando e reforçando formas de concorrência e rivalidade permanentes e exacerbadas.

Apoiada em Deleuze e em um conjunto extenso de autores, Haroche (idem, p. 672) analisa a política e cultura da avaliação hoje vigente e os efeitos perversos daquilo que chama de "nivelamento e igualitarismo sobre a atividade do pensamento", que se traduz pela submissão a normas, regras e objetivos de uma produtividade intensa, que invadiu as humanidades e restringiu o espírito de liberdade, de autonomia e criatividade que a caracterizavam. Condenando a lógica empresarial bastante presente nos meios acadêmicos contemporâneos (que ela denomina de "produtividade cega e desengajada"), a autora defende que o papel do saber seja valorizado em termos de profundidade e duração, e não como vigora hoje, em termos de extensão e superfície. Suas argutas palavras não somente nos fazem lembrar dos riscos envolvidos no ritmo agitado (frenético) em que vivemos, como nos ajudam a ter uma visão crítica acerca de alguns excessos presentes na sociedade atual:

O trabalho do pensamento é acompanhado de tempos mortos, de momentos inúteis, de momentos de flutuações, de pausas, de diversões, de digressões, momentos que alimentam um trabalho invisível que se desenvolve na duração e que supõe uma parte inavaliável.

5 Para uma análise pormenorizada dessa temática, ver Rego (2014). 
Este inavaliável corresponde a um direito fundamental: o direito de não falar, de se calar, o direito de não ter que produzir e se produzir de maneira contínua - seja qual for o sentido da palavra produzir ou se produzir - para se poder pensar, fazer, se ativar, criar, mostrando-se atento ao que as humanidades nos transmitem: a medida no sentido em que se é medido, ou se fica medido.

"A avaliação contínua" tende a despojar o indivíduo da liberdade interior, da experiência interior, do pensamento, "o trabalho do pensamento consiste realmente em conferir ao cálculo um significado, relacionando sempre as quantidades medidas a um sentido de medida". Um sentido medido ou um sentido repousando sobre a cifra. Porém, "confundir medida e avaliação nos condena a perder o sentido da medida. Porque avaliar não é somente medir, mas referir a medida a um julgamento de valor que lhe confere um sentido". (Haroche, 2011, p. 675)

Esse é apenas um exemplo, entre muitos outros possíveis, de como compreender tanto os nexos e fios que ligam a escrita dos memoriais ao ambiente acadêmico mais amplo quanto o contexto social e político no qual eles foram ou estão sendo elaborados. Enfim, ao cenário histórico em que os textos são produzidos e seus autores avaliados.

\section{CONSTRUÇÃO DAS IDENTIDADES, A NARRATIVA SOBRE ELAS E OS TRABALHOS DA MEMÓRIA}

Uma outra característica singulariza o memorial e merece ser destacada: como o passado é sempre visto, interpretado e significado com os olhos do presente, esse tipo de escrita acadêmica apresenta também a importante peculiaridade de permitir o exame das relações existentes entre memória, identidade e narrativa. Temas complexos, mas fundamentais para qualquer um que tenha interesse no campo das ciências humanas e sociais.

Estudos já clássicos e outros mais recentes (em história, sociologia, psicologia e antropologia) mostram como a construção identitária não se manifesta apenas no conteúdo dos enunciados, mas nas escolhas ligadas à propria narrativa e aos trabalhos da memória. Essa pode ser uma boa síntese das relações dialéticas estabelecidas entre memória, identidade e narrativa: elas se conjugam, se nutrem mutuamente, se apoiam umas nas outras para produzir versões de trajetórias de vida, de um mito, de personagens, de fatos e feitos e até versões de si mesmas (Bruner; Weisser, 1995; Delory-Momberger, 2008; Dosse, 2009; Dubar, 2006; Elias, 1994; Ginzburg, 2007; Halbwachs, 1990; Middleton; Brow, 2006).

Isso significa que, ainda que constrangidos pelos limites do gênero, os autores dos memoriais deixam transparecer um trabalho ativo: "a marca do narrador, como a mão do oleiro na argila do vaso" (Benjamin, 1985, p. 205). Ou seja, suas perspectivas subjetivas, o modo singular - mas que simultaneamente é plural e coletivo - de 
relatar como circunscreveram seus caminhos, suas opções metodológicas, suas intenções práticas e suas experiências formadoras.

É interessante observar que os contornos, referências e fronteiras dessas narrativas sempre se colocam de maneira provisória. São, portanto, permanentemente passíveis de novos arranjos: podem se alargar ou se estreitar, avançar ou retroceder, se expandir ou se fechar. Capítulos podem ser agregados; outros suprimidos. O epílogo pode virar o começo. A história não tem um começo nem um final já escrito. Nesse sentido, seria mais interessante falarmos em identidades narrativas (Dosse, 2009; Hermans; Dimaggio, 2007; Ricoeur, 1995), fugazes ou multifacetadas (Bauman, 2005; Hall, 2003; Rose, 2001).

Joël Candau (2011, p. 66-67) traz, em livro recentemente traduzido para o português, Memória e identidade, explicações muito oportunas sobre a imagem que desejamos construir de nós mesmos por meio de elementos do passado, das contingências do presente e dos nossos projetos para o futuro:

Nossa memória acrescenta à lembrança o futuro dessa lembrança. [...] O tempo da lembrança é, portanto, inevitavelmente diferente do tempo vivido, pois a incerteza inerente a este último está dissipada no primeiro. Isso pode explicar os numerosos casos de embelezamento de lembranças desagradáveis que, ao serem relembradas, são aliviadas da angústia e do sentimento de contrariedade provocados pela incerteza da situação vivida durante a qual se teme sempre o pior $[\ldots]$.

Em síntese, a elaboração dos memoriais revela um pouco do complexo jogo que acompanha a construção das identidades, a narrativa sobre elas e os trabalhos da memória. E é isso que particularmente me interessa aprofundar e que considero potencialmente fértil para o campo da educação. A narrativa, longe de ser uma apresentação isenta de um conjunto estável de características que compõem uma personalidade inequívoca e/ou uma simples evocação daquilo que se passou, é uma construção elaborada, dinâmica, que sempre se renova. É justamente o distanciamento do passado, explica Candau (idem, p. 71), que permite ao sujeito reconstruir uma narrativa com base em uma "mistura complexa de história e ficção, de verdade factual e verdade estética":

[...] De fato, o ato de memória que se dá a ver nas narrativas de vida e nas autobiografias coloca em evidência essa aptidão especificamente humana que consiste em dominar o próprio passado para inventariar não o vivido, como supunha Maget, mas o que fica do vivido. O narrador parece colocar em ordem e tornar coerente os acontecimentos de sua vida que julga significativos no momento mesmo da narrativa: restituições, ajustes, invenções, modificações, simplificações, "sublimações", esquematizações, esquecimentos, censuras, resistências, não ditos, recusas, "vida sonhada", ancoragens, interpretações e reinterpretações constituem a trama desse ato de memória que é sempre uma excelente ilustração das estratégias identitárias que operam em toda narrativa. 
Esse conjunto de traços que caracterizam os memoriais justificam, por sua vez, o interesse em pesquisá-los. Mais que mero componente de um programa de avaliação, os memoriais representam, conforme alerta feito por Rocco (1993, p. 40), "peças importantes para registrar e descrever uma dimensão da universidade - aquela que revela a história e pontua a trajetória acadêmica de seus professores". Ainda de acordo com suas palavras:

Conhecemos os colegas. Conversamos com eles. Lemos seus livros. Ouvimos sobre seu desempenho docente e seus trabalhos. Mas pouco sabemos de seus percursos, das lutas, dificuldades e conquistas. Afinal quem são esses professores? De onde vieram? Como foram formados? Quais as suas preocupações e contribuições fundamentais? Enfim de que forma passaram ou estão passando pela vida acadêmica?

Um pouco na vertente dos estudiosos dos Anais e na esteira das contribuições da Nova História, acredito que seriam benvindos e oportunos trabalhos - dissertações, teses, pesquisas temáticas - que levantassem e estudassem grupos de memoriais.

Análises de tal ordem, por certo, permitiriam pensar sob outros focos a carreira do professor universitário e também olhar, com outras lentes, a própria história da Universidade. (idem, ibidem)

\section{CONSIDERAÇÕES FINAIS}

Os resultados obtidos com a pesquisa realizada permitem afirmar que a prática de escrever e analisar narrativas em primeira pessoa guarda um grande potencial ainda pouco explorado no contexto brasileiro. No caso específico dos memoriais, reitero que, no meu entender, eles deveriam ultrapassar a destinação única de apresentação nas bancas de concurso. Tais textos merecem ser mais conhecidos, valorizados e explorados como fontes documentais capazes de gerar pesquisas muito interessantes sobre um amplo espectro de temas, como, por exemplo, a compreensão da história da profissão docente e das práticas escolares, dos modos de pesquisa na universidade em um passado recente e no cenário contemporâneo, da formação de professores, do processo de construção de identidades docentes no ensino superior, entre outros.

Não podemos esquecer que, embora restringido pelas formalidades do gênero, o memorial é um dos raros espaços acadêmicos em que o pesquisador está de algum modo autorizado a estabelecer relações entre as dimensões cognitivas e afetivas, e em que, portanto, pode "baixar a guarda" e comentar, ainda que com certa limitação e com altas doses de autocensura, aspectos de sua vida privada que podem ajudar a compreender facetas interessantes envolvidas em sua trajetória profissional e intelectual.

Ainda que não seja esse o objetivo, os memoriais ajudam-nos a conhecer também traços importantes relacionados à vida nas universidades, à formação de 
novos pesquisadores e linhas de pesquisa, a percursos e carreiras de docentes no ensino superior. Auxiliam também a lembrar o quanto, e de que maneira, alguns professores marcaram a formação dos autores dos relatos. Simultaneamente, os memoriais permitem entrever como esses professores foram importantes para sua geração e para seu grupo de orientandos. Sendo assim, são testemunhos que conseguem contextualizar e dar algum sentido ao conhecimento que produzido por esses profissionais ao longo de muitas solitárias horas de trabalho e estudo e, ao mesmo tempo, ao conhecimento que eles ajudaram outros pesquisadores a construir por meio da consolidação de uma linha de pesquisa.

Os textos trazem também informações interessantes sobre as experiências que viveram como leitores e como alunos ao longo da sua trajetória escolar e ainda elementos que se conectam com seu ofício docente e sua prática como professores. Ajudam a elucidar ainda alguns gestos de rebeldia, algumas lutas travadas em períodos de maior engajamento ou militância, assim como retratam algumas desilusões, desencantos e sonhos perdidos.

É igualmente interessante observar a forma como os indivíduos se deixaram afetar pelos discursos acadêmicos dominantes, pelos autores, leituras e paradigmas da moda (quando eram estudantes ou quando já haviam se tornado professores) e como conseguiram, ao mesmo tempo, atender ou ajustar essas demandas hegemônicas aos seus próprios interesses, às suas experiências de vida e aos problemas com os quais se depararam durante sua existência. No memorial temos a rara possibilidade de entender, de um só golpe, um pouco das condições de vida, dos conflitos sociais da época, das consternações do pesquisador/escritor e, sobretudo, das motivações, perguntas, obsessões e dilemas que o levaram a se engajar em determinada carreira ou a perseguir determinado programa de pesquisa.

Desse modo, os memoriais falam de cada um, mas também das aspirações de uma geração de estudantes, pesquisadores e profissionais. $\mathrm{O}$ estudo dos memoriais - como de outros textos (auto)biográficos - permite identificar a íntima, permanente e dialética relação existente entre o indivíduo, os "outros sociais" e a cultura (Vigotski, 2000; Wallon, 1975). Possibilita também perceber que o indivíduo sempre estabelece uma relação ativa com os outros sujeitos, com a realidade e com as condições de vida que se apresentam.

Os relatos evidenciam que nenhuma história corre sozinha e que o sujeito não é determinado apenas pelas injunções e contingências de seu meio ou pelas grandes forças impessoais que são capazes de determinar o rumo das criações humanas. Ao contrário, eles deixam claro como os acontecimentos históricos cruciais de um tempo e lugar, traduzidos nos "discursos hegemônicos", no "espírito de uma época" ou nos "emblemas de uma geração" se entrecruzam com fatos cotidianos enfrentados de modo singular por cada um dos depoentes e, principalmente, com a maneira imprevisível como esses acontecimentos afetam a vida de cada um, bem como os modos idiossincráticos que os indivíduos encontram ao lidar com os fatos e episódios vividos. 
Ao examinarmos um conjunto de depoimentos dessa natureza, nos convencemos também de que nenhuma criação artística ou científica é um processo mecânico, totalmente desligado da vida do criador e de suas preocupações existenciais mais ou menos intensas, bem como do clima histórico de uma época e de um lugar. Como disse Vygotski (2009, p. 42) ao escrever sobre imaginação e criação na infância: "Qualquer inventor, mesmo um gênio, é sempre um fruto de seu tempo e de seu meio [...]. Nenhuma invenção ou descoberta científica pode emergir antes que aconteçam as condições materiais e psicológicas necessárias para seu surgimento". Em outras palavras: a possibilidade de criação do novo não acontece no vazio, e sim na trama social, por meio do trabalho, das descobertas, dos conhecimentos e ideais dos outros. Por essa razão, a criação no nível individual estará sempre historicamente situada, expressando um modo idiossincrático de apropriação do legado cultural elaborado por outros sujeitos, em outras épocas e circunstâncias.

\section{REFERÊNCIAS}

Arida, Pérsio. Rakudianai: memórias vertiginosas. Piauí, Rio de Janeiro, n. 55, p. 20 -46, abr. 2011.

Bakhtin, Mikhail. Estética da criação verbal. São Paulo: Martins Fontes, 1992.

Bauman, Zygmunt. Identidade. Rio de Janeiro: Jorge Zahar, 2005.

Benjamin, Walter. Obras escolhidas: magia e técnica, arte e política. São Paulo: Editora Brasiliense, 1985.

Bourdieu, Pierre. A ilusão biográfica. In: Ferreira, Marieta de Moraes; Amado, Janaina P. (Orgs.). Usos E $\mathcal{E}^{2}$ abusos da história oral. 7. ed. Rio de Janeiro: FGV, 2005, p. 183-191.

Bruner, Jerome; Weisser, Susan. A invenção do ser: a autobiografia e suas formas. In: Olson, David Richard; Torrance, Nancy. Cultura escrita e oralidade. São Paulo: Ática, 1995.

Burke, Peter. A anatomia da biografia. Folha de São Paulo, São Paulo, Suplemento Mais, p. 12, 2 fev. 2003.

Candau, Joël. Memória e identidade. Tradução de Maria Letícia Ferreira. São Paulo: Contexto, 2011.

CAndido, Antonio. A vida ao rés-do-chão. In: A crônica. O gênero, sua fixação e suas transformações no Brasil. Campinas: Editora da UNICAMP; Rio de Janeiro: Fundação Casa de Rui Barbosa, 1992, p. 13. mar. 2012

. Arte naquele tempo (memórias). Revista IEB, São Paulo, n. 54, p. 13-20, set./

Delory-Momberger, Christine. Biografia e educação: figuras do indivíduo-projeto. São Paulo: Paulus; Natal: EDUFRN, 2008. (Coleção Pesquisa (Auto)Biográfica-Educação) Dosse, François. O desafio biográfico: escrever uma vida. São Paulo: Edusp, 2009. 
Dubar, Claude. A crise das identidades: a interpretação de uma mutação. Porto: Edições Afrontamento, 2006.

Elias, Norbert. A sociedade dos individuos. São Paulo: Jorge Zahar, 1994.

Ginzburg, Carlo. O fio e os rastros: verdadeiro, falso, fictício. São Paulo: Companhia das Letras, 2007.

Halbwachs, Maurice. A memória coletiva. São Paulo: Vértice, 1990.

HALL, Stuart. Identidade cultural na pós-modernidade. 8. ed. Rio de Janeiro: DP\&A, 2003. Haroche, Claudine. O inavaliável em uma sociedade de desconfiança. Educação e Pesquisa, São Paulo, USP, v. 37, n. 3, p. 657-676, set./dez. 2011.

Hermans, Hubert J. M.; Dimaggio, Giancarlo. Self, identity, and globalisation in times of uncertainty: a dialogical analysis. Review of General Psychology, American Psychological Association, v. 11, n. 1, p. 31-61, mar. 2007.

Houaiss, Antonio; Villar, Mauro de Salles; Fraco, Francisco Manoel de Mello. Dicionário Houaiss da lingua portuguesa. Rio de Janeiro: Objetiva, 2001.

Larrosa, Jorge. Notas sobre a experiência e o saber de experiência. Revista Brasileira de Educação, Rio de Janeiro, n. 19, p. 20-28, jan./abr. 2002.

MeLucci, Alberto. O jogo do eu: a mudança de si em uma sociedade global. São Leopoldo: UNISINOS, 2004.

Middleton, David; Brown, Steve D. A psicologia social da experiência: a relevância da memória. Pro-Proposiçcoes, Campinas: Unicamp, v. 17, n. 2 (50), p. 71-97, maio/ago. 2006. Oliveira, Marta Kohl. Cultura E psicologia: questões sobre o desenvolvimento do adulto. São Paulo: Hucitec, 2009.

Oliveira, Marta Kohl; Rego, Teresa Cristina; Aquino,Julio Groppa. Desenvolvimento autobiográfico e constituição de subjetividades. Pro-Posiçôes (Dossiê Temas e Tendências na perspectiva histórico-cultural),Campinas: Unicamp, v. 17, n. 2 (50), maio/ago. 2006. Passeggi, Maria da Conceição. Memoriais autobiográficos: a arte profissional de tecer uma figura pública de si. In: Passeggi, Maria da Conceição; Barbosa, Tatyana Mabel Nobre (Orgs.). Memórias, memoriais: pesquisa e formação docente. Natal: EDUFRN; São Paulo: Paulus, 2008.

Rego, Teresa Cristina. Memórias da escola: cultura escolar e constituição de singularidades. Petrópolis: Vozes, 2003.

. Produtivismo, pesquisa e comunicação científica: entre o veneno e o remédio. Educação e Pesquisa, São Paulo: USP, v. 40, n. 2, p. 325-346, jun. 2014.

Ricoeur, Paul. Tempo e narrativa. São Paulo: Papirus, 1995. tomo II.

Rocco, Maria Thereza Fraga. Memorial apresentado para concurso de professor titular. São Paulo: Faculdade de Educação da Universidade de São Paulo, 1993.

Rose, Nikolas. Inventando nossos eus. In: Silva, Tomaz Tadeu. Nunca fomos humanos: nos rastros do sujeito. Belo Horizonte: Autêntica, 2001. 
Sarlo, Beatriz. Tempo passado: cultura da memória e guinada subjetiva. São Paulo: Companhia das Letras, 2007.

SoAres, Magda Becker. Metamemória-memórias: travessia de uma educadora. 2. ed. São Paulo: Cortez, 2001.

Valsiner,Jean; Rosa, Alberto (Orgs.). The Cambridge handbook of sociocultural psychology. Cambridge: Cambridge University Press, 2007.

Vigotski, Lev Seminovitch. Manuscrito de 1929 [Psicologia concreta do homem]. Tradução de Alexandra Marenitch. Educação E̊ Sociedade, Campinas: CEDES, ano XXI, n. 71, jul. 2000.

. Imaginação e criação na infância. São Paulo: Ática, 2009.

Wallon, Henri. Objetivos e métodos da psicologia. Lisboa: Estampa, 1975.

Wertsch, James V. Voices of collective remembering. Cambrigde: University Press, 2002.

\section{SOBRE A AUTORA}

Teresa Cristina Rego é doutora em educação pela Universidade de São Paulo (USP). Professora associada da mesma instituição.

E-mail: teresare@usp.br

Recebido em outubro de 2012

Aprovado em novembro de 2013 